\section{Membrane Filtration in Water Recycling - Removal of Natural Hormones}

L.D. Nghiem, A.I. Schäfer, T.D.Waite

Centre for Water \& Waste Technology

School of Civil \& Environmental Engineering, UNSW

Sydney NSW 2052

$\mathrm{Ph} 0293854470$

Fax 0293856139

Email A.Schaefer@unsw.edu.au

\section{INTRODUCTION}

Recent detections of endocrine-disrupting chemicals (EDCs) in effluent are of great concern by sections of the community associated with the issue of reclaimed water recycling. In vitro and in vivo studies by many researchers have confirmed the impacts of EDCs on trout at the common concentration encountered in sewage effluent. Amongst many types of EDCs the impacts of steroid estrogens such as estrone, estradiol (natural hormones) and ethinylestradiol (a synthetic hormone) are prominent as they have far higher endocrine-disrupting potency than other synthetic EDCs (Johnson and Stumpter, 2001). Performance of conventional wastewater treatment of different plants on removal of these compounds varies greatly and, concentrations of some steroid estrogens in secondary effluent are still able enough to harm wildlife such as fish in particular (Johnson and Stumpter, 2001). In spite of the magnitude of this problem, research on the removal of EDCs in water and wastewater treatment remains to date very limited due to their relatively low concentration and the associated analytical difficulties.

Table 1: Membrane types and pure water flux

\begin{tabular}{cccc}
\hline Membrane Type & $\begin{array}{c}\text { Average Pure Water } \\
\text { Flux }\end{array}\left[\begin{array}{c}\text { Membrane } \\
\left.\text { [es } \mathrm{h}^{-1}\right]\end{array}\right.$ & Membrane material \\
resistance $\left[\mathrm{m}^{-1}\right]$ & \\
\hline TFC-S & $55.0 \pm 7.3$ & $3.3 \cdot 10^{13}$ & Polyamide on \\
TFC-SR2 & $77.0 \pm 25.2$ & $2.3 \cdot 10^{13}$ & Polysulfon support \\
\hline
\end{tabular}

${ }^{*}$ Average values are derived from all experiments and variations are averaged.

Given the continuous developments in membrane technology, tertiary treatment using membrane processes has been identified as a promising technology to provide a safeguard to water recycling practice and to protect the environment. Several researchers have shown that nanofiltration is capable of removing trace organics including natural hormones and a wide range of pesticides (Kiso et al, 2001; Schäfer et al, 2001; Kiso et al, 2000). In our previous work, removal of trace contaminant estrone using eight different nanofiltration and reverse osmosis membranes, which cover a wide pore size range, has been studied. It was found that estrone could be adsorbed to the surface by some membranes. This adsorptive phenomenon is of concern as it may result in contaminants leakage or bulk release when desorption occurs. This paper investigates retention nanofiltration membranes TFC-SR2 and TFC-S.

\subsection{Membranes and filtration process}

TFC-S and TFC-SR2 were selected for this study due to their excellent permeability at low pressure. They were supplied by Fluid System (San Diego, USA). Membrane types and pure water flux at 5 bar are summarised in Table 1. TFC-S is expected to have a smaller pore size as compared to TFC-SR2 due to its higher salt retention (data is not shown) and pure water flux differences.

A schematic of the filtration system is shown in Figure 1. Experiments were carried out in a $185 \mathrm{~mL}$ stainless steel stirred cell. The inner diameter was $56.6 \mathrm{~mm}$ resulting in a membrane surface area of $21.2 \times 10^{-4} \mathrm{~m}^{2}$. An Amicon magnetic stirrer was used and the stirrer speed was set at $400 \mathrm{rpm}$. Instrument grade air was used to pressurize the stirred cell. A new membrane was at $400 \mathrm{rpm}$. Instrument grade
used for each experiment.

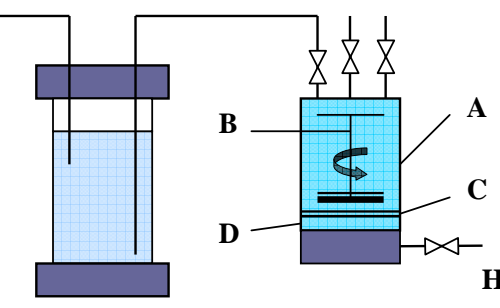

A Stirred cel

B Magnetic stirrer

C Membrane

D Stainless steel porous support

E $2 \mathrm{~L}$ reservoir

$F \quad$ Pressurised instrument air inlet

H Permeate outlet
G Feed inlet, safety and release valves

Figure 1: Membrane filtration stirred cell set-up

After compacting the membranes using MilliQ water at 10 bar for 1 hour, feed solution was filtered at 5 bar and six permeate samples of $20 \mathrm{~mL}$ each were collected from a feed volume of $185 \mathrm{~mL}$. A retentate sample was also collected for analysis.

Parameters used to quantify the efficiency of a membrane were flux $(J)$ and solute retention $(R)$ where the flux is defined as $J \equiv \frac{1}{A} \frac{d V}{d t}$ and retention as $R=100 \cdot\left(1-\frac{c_{P}}{c_{B}}\right)$.

\section{Chemicals and analysis}

All chemicals were of analytical grade. Radiolabelled estrone-2,4,6,7- ${ }^{3} \mathrm{H}(\mathrm{N})$ was purchased from Sigma Aldrich (Saint Louis, Missouri, USA). The background electrolyte consisted of $1 \mathrm{mM}$ $\mathrm{NaHCO}_{3}$, and $20 \mathrm{mM} \mathrm{NaCl}$. pH was adjusted using $1 \mathrm{M} \mathrm{HCl}$ or $1 \mathrm{M} \mathrm{NaOH}$.

\subsection{Natural Hormone Characteristics and Analysis}

Both estrone and estradiol are hydrophobic compounds and have a very low solubility in water (Merck, 1996). The acid dissociation constant, pKa, of estrone is 10.4 (Schäfer et al, (submitted)). Estradiol has a very similar molecular structure as estrone; thus, it is expected to have the same pKa value. Hydroxyl and carbonyl functional groups of estrone and estradiol make them capable of participating in hydrogen bonding, as a proton-donor or proton-acceptor species.

Feed solution was prepared by spiking estrone or estradiol into background electrolyte solution to make up $100 \mathrm{ng} / \mathrm{L}$ of estrone or estradiol, respectively. This is a typical concentration of natural hormones often encountered in surface waters and wastewaters.

Estrone was analysed using a Packard Instruments scintillation counter. 
Nghiem, D.L. ; Schäfer, A.I. ; Waite, T.D. (2003) Membrane filtration in water recycling: removal of natural hormones, Water Science \& Technology: Water Supply 3, 3, 155-160.

\section{Results And Discussion}

\subsection{Effect of $\mathrm{pH}$ on adsorption of estrone}

As indicated previously, eight membranes were screened for estrone retention and from that result two membranes were selected for further study; the TFC-SR2 and TFC-S due to an expected difference in pore dimension based on pure water flux (see Table 1) and salt retention.

Figure 2 shows that adsorption of estrone by both membranes drops drastically with the dissociation of estrone at $\mathrm{pH} 10.5$. It is not surprising that adsorption capacity of the two membranes is almo membranes is almost identical as they are both of polyamide on polysulfon support. The experiments do not allow to distinguish between adsorption on the active layer and the support material.

Hydrogen bonding was suggested as the mechanism of adsorption of estrone by the membrane (Schäfer et al. (submitted)). Hydroxyl groups are the most likely interaction iydroxyl groups are the most likely interaction sites due to the resonance structures of the aromalic groups. When dissociated, estrone loses its proton and becomes unable to participate in hydrogen bonding with membrane functional groups, resulting in a reduction in adsorption and lower retention.

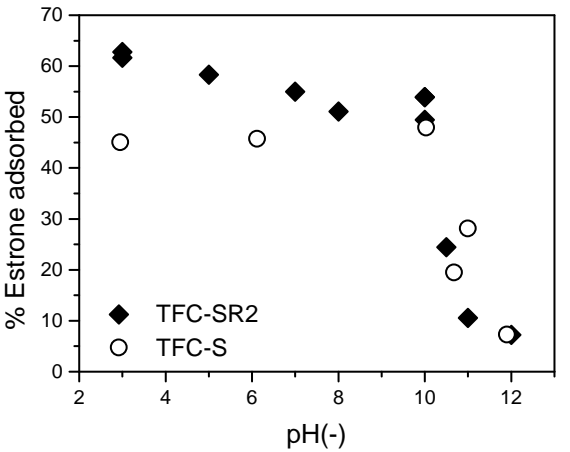

Figure 2: Estrone adsorption as a function of $\mathrm{pH}$ on TFC-SR2 and TFC-S membranes (100 $\mathrm{ng} / \mathrm{L}$ estrone; $1 \mathrm{mM} \mathrm{NaHCO} ; 320 \mathrm{mM} \mathrm{NaCl}$ ).
3.2 Adsorption effect on estrone and estradiol retention
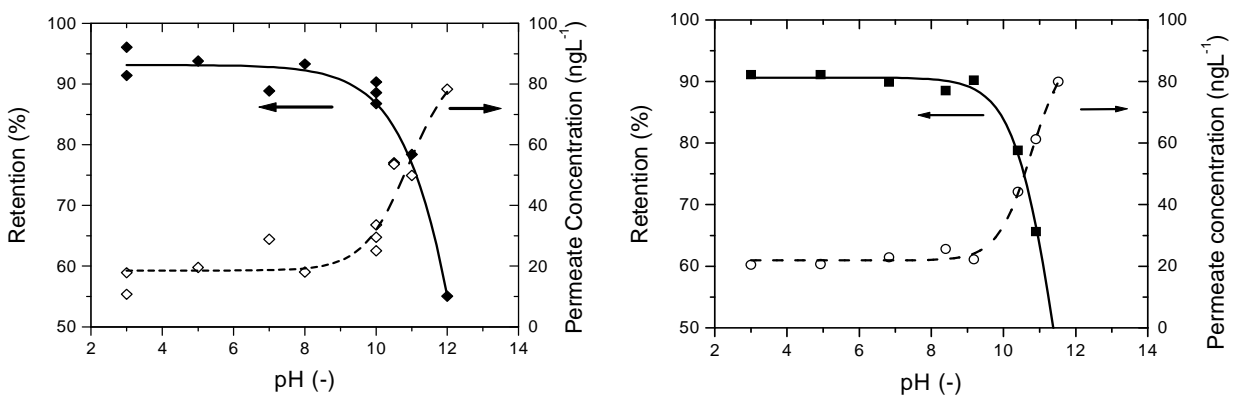

Figure 3: Permeate concentration and retention of estrone (right) and estradiol (left) by TFC-SR2 membrane as function of $\mathrm{pH}\left(100 \mathrm{ng} / \mathrm{L}\right.$ estrone or estradiol; $1 \mathrm{mM} \mathrm{NaHCO}_{3}$ and $\left.20 \mathrm{mM} \mathrm{NaCl}\right)$.

Figure 3 compares retention of estrone and estradiol by TFC-SR 2 at different $\mathrm{pH}$. Retention of both compounds decreases drastically as $\mathrm{pH}$ exceeds their $\mathrm{pKa}$ value (10.5) in parallel with the decreased adsorption (see Figure 2 for estrone). Given the similarity between estrone, estradiol and other estrogenic compounds, this result indicates that similar adsorption phenomena by the membranes can be expected for other estrogenic compounds such as estriol or ethinylestradiol.

3.3 Time Dependence of Adsorption

It appears that adsorption of trace contaminants on membranes is a temporary effect in initial stages of filtration. While this adsorption should not be relied upon for the removal of trace contaminants, adsorption is likely to continue until the material is saturated and lead to the accumulation of large amounts of contaminants.

To investigate the limits of this adsorption and subsequent retention of saturated membranes, experiments were conducted with a series of fresh feed solutions for one membrane. Results from those experiments are presented in

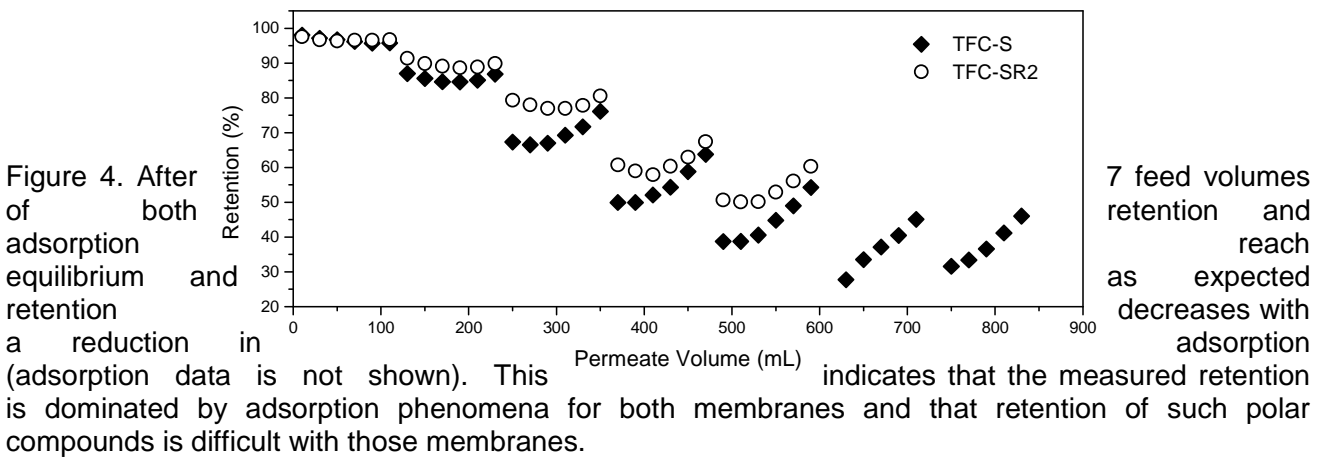

Figure 4: Retention as a function of filtration volume (100 ng/L estrone; $1 \mathrm{mM} \mathrm{NaHCO}_{3}, 20 \mathrm{mM} \mathrm{NaCl}$ and $\mathrm{pH}$ 7.8).

\section{CONCLUSIONS}

Both estrone and estradiol could be significantly adsorbed by the membranes. $\mathrm{pH}$ can significantly influence the adsorption process, presumably due to hydrogen bonding. Consequently, this leads to an accumulation of trace contaminants in the membrane and possible bulk release of those contaminants when desorption is favour.

Further studies are planned to investigate the adsorption phenomena of all eight membranes to eliminate a membrane where retention is not determined by adsorption to achieve a stable retention performance, ideally in conjunction with a very low adsorption capacity to reduce the risk of a bulk release of trace contaminants.

\section{ACKNOWLEDGEMENTS}

The Queensland Government and the Australian Research Council are thanked for project funding We acknowledge Koch Membrane Systems (San Diego, US) for providing membrane samples.

\section{SymBOLS}


Nghiem, D.L. ; Schäfer, A.I. ; Waite, T.D. (2003) Membrane filtration in water recycling: removal of natural hormones, Water Science \& Technology: Water Supply 3, 3, 155-160.
A: $\quad$ Membrane Surface $\left[\mathrm{m}^{2}\right]$ Bulk Concentration [mgL
$\mathrm{J}: \quad$ Flux $\left[\mathrm{Lm}^{-2} \mathrm{~h}^{-1}\right]$
V: $\quad$ Permeate Volume [L]
$\mathrm{C}_{\mathrm{P}}$ : Permeate Conc. $\left[\mathrm{mgL}^{-1}\right]$

\section{References}

Johnson, A.C and Sumpter, J.P. (2001). Removal of Endocrine-Disrupting Chemicals in activated sludge treatment works. Environmental Science \& Technology, 35, 4697-4703.

Kiso, Y., Kon, T., Kitao, T., Nishimura, K. (2001). Rejection properties of alkyl phthalates with nanofiltration membranes. Journal of Membrane Science, 182, 205-214.

Kiso, Y., Nishimura, Y., Kitao, T., Nishimura, K. (2000). Rejection properties of non-phenylic pesticides with nanofiltration membranes. Journal of Membrane Science, 171, 229-237.

Merck, B.S. (1996). Merck index. $12^{\text {th }}$ Ed. Merck \& Co., Inc, New Jersey.

Schäfer, A.I., Nghiem, D.L., Waite, T.D. (2001). Removal of natural hormone estrone from Water and

Wastewater using Nanofiltration and Reverse Osmosis (Submitted to Environmental Science \&

Technology). 